\title{
Modelo para estabelecer competências para o futuro do design orientado pelas tecnologias emergentes
}

\section{Model to establish skills for the future of design oriented by emerging technologies}

\author{
Christian Costa, UFPR \& UTFPR \\ christiane.ogg@gmail.com
}

\author{
Alexandre Pelegrini,UFPR \& UTFPR \\ avpelegrini@gmail.com
}

\begin{abstract}
Resumo
Este estudo apresenta o desenvolvimento de um modelo auxiliar para a construção de competências para o futuro do design, orientado pelas tecnologias emergentes. O método design science research foi utilizado para a identificação, desenvolvimento e avaliação do modelo. Na fase de instanciações foram realizados sete workshops para a construção colaborativa das competências com o objetivo de testar e avaliar o modelo desenvolvido. Docentes, discentes e profissionais do design analisaram as possíveis sinergias entre as tecnologias emergentes e elencaram competências para novas práticas de design habilitadas por estas. A validação se deu por meio de formulários online e entrevistas com profissionais atuantes demonstrando a eficácia do modelo proposto. Conclui-se que para manter sua relevância o ensino do design precisa basear suas ações na antecipação do futuro, estabelecendo novas competências para o design e que o modelo proposto pode ser uma solução satisfatória para o problema identificado.
\end{abstract}

Palavras-chave: Tecnologias emergentes, Competências para o design, Design science research.

\begin{abstract}
This study presents the development of an auxiliary model to build competencies for the future of design, driven by emerging technologies. The design science research method was used for the identification, development and evaluation of the model. In the instantiations phase, seven workshops were held for the collaborative construction of competencies in order to test and evaluate the developed model. Professors and students of design courses, and professionals in the area analyzed the possible synergies between emerging technologies and listed competencies for new design practices enabled by them. The validation was done through online forms and interviews with active professionals demonstrating the effectiveness of the proposed model. In order to maintain its relevance, design education needs to base its actions on anticipating the future, establishing new design competencies and that the proposed model can be a satisfactory solution to the identified problem.
\end{abstract}

Keywords: Emerging technologies, Design competencies, Design science research. 


\section{Introdução}

O rápido desenvolvimento das tecnologias digitais nos últimos anos gerou grandes desafios para a prática e o ensino de design. As tecnologias de abordagem distribuída possibilitaram a abertura e compartilhamento de dados, a produção entre pares e novos comportamentos colaborativos obscurecendo a linha que separava usuários e designers. Segundo Smith et al. (2013), a integração das tecnologias de fabricação digital gera novas possibilidades de reconfiguração da produção e do consumo possibilitando novas formas de organização social, novos comportamentos produtivos, econômicos e de sustentabilidade.

As tecnologias denominadas emergentes são aquelas que têm o potencial para criar ou transformar a sociedade nos próximos anos, mas que ainda não se consolidaram. "São tecnologias que geralmente já possuem aplicações práticas, despertam grande interesse por seu potencial de rápido crescimento e impacto na sociedade, mas ainda não foram plenamente exploradas" (Einsiedel, 2009). Estas tecnologias abrem um novo panorama para que o design possa se reinventar, buscando novas formas de atuação, fazendo novas conexões e combinações definindo sua própria agenda para mudanças positivas.

Expande-se assim o escopo das atividades do design para além da concepção de objetos, passando para o campo das interações, sistemas e ambientes, possibilitando a criação de cadeias de valor inovadoras e disruptivas. A mudança no foco, nas práticas e no papel do design requer novas competências orientadas às novas tecnologias que geralmente já possuem aplicações práticas, mas ainda não foram plenamente exploradas.

Porém, o ensino não pode aguardar para que as práticas ocorram, o ensino deve antever e se antecipar para preparar os alunos para o futuro. $\mathrm{O}$ ensino de design neste sentido torna-se um desafio para professores e alunos, pois sofrer as mudanças de forma passiva ou agir na urgência por reatividade não trazem soluções profundas para o problema. A oportunidade se coloca na preparação para as mudanças previsíveis pela pró-atividade e na ação para provocar mudanças desejadas.

Para Manzini (2011), as escolas de design são locais onde a próxima geração de designers é formada e este papel educativo pode ser considerado como um investimento para o futuro. "Para que o ensino cumpra seu potencial papel de agente de mudança, é preciso formar atores críticos, criativos e competentes, envolvendo-os em problemas, oportunidades e métodos de design que hoje parecem radicalmente novos e ainda envolvem um pequeno número de minorias ativas".

Ao se antecipar e promover uma reflexão crítica às tecnologias emergentes, que não estão sendo ainda amplamente utilizadas, os designers poderão propor sistemas e objetos com valores sociais mais amplos. Pois, " uma vez que os compromissos iniciais são assumidos, as escolhas tendem a se tornar fortemente fixadas no equipamento material, no investimento econômico e no hábito social, e assim, a flexibilidade original desaparece para qualquer propósito prático" (Winner, 1986).

Portanto, o momento exige um repensar da pedagogia, do conteúdo e das competências, levando em consideração o conhecimento complexo, necessário em várias esferas que convencionalmente não fazem parte da prática do design e das disciplinas do currículo tradicional. 
Este novo aprendizado necessita ir além do existente, introduzindo competências e a compreensão das novas tecnologias no ensino do design, proporcionando ao aluno uma compreensão da mudança de paradigma que a integração destes desenvolvimentos digitais está criando na prática da profissão (LOY, 2015).

A elaboração de programas de design se torna uma tarefa dificil para as escolas de design que pretendem uma abordagem atual reconhecendo a complexidade e variedade de opções possíveis para a atuação do design. Para Imbesi (2011), "esta é uma oportunidade de elaborar programas de design para produzir, reunir e dar visibilidade a experiências de design crítico, emergindo como um espaço alternativo e espontâneo, muitas vezes paralelamente e em correlação com a produção oficial estabelecida".

De Vere (2013) cita que "a profissão de design industrial está à beira de um renascimento", uma vez que designers e consumidores são capacitados por novas tecnologias que aumentam a criatividade e a inovação, facilitam as novas práticas de desenvolvimento de produtos, permitem o empreendedorismo de design e incentivam uma cultura participativa.

Os modelos de competências existentes na literatura não abordam as novas práticas baseadas nas tecnologias emergentes, as quais estão sendo desenvolvidas nas práticas e no ensino do design em caráter experimental. As Diretrizes Curriculares Nacionais do Curso de Graduação em Design minimizam a dimensão das competências coletivas e sociais, estão vinculadas aos paradigmas da produção industrial, à ótica do mercado e limitam-se à descrição de funções e tarefas dos processos produtivos (Angélico e Oliveira, 2017; Deluiz, 2010).

Para construir um quadro de competências visando o futuro do design surge a necessidade da elaboração de um modelo específico, que instigue a reflexão acadêmica e auxilie a construção colaborativa de competências para a formação do designer, orientado pelas tecnologias emergentes.

\section{Construção de competências para o futuro}

Competência, segundo Perrenoud (1999), "é a capacidade de agir eficazmente em um determinado tipo de situação, apoiada em conhecimentos, mas sem limitar-se a eles". Uma competência que se manifesta na execução de uma tarefa não é, portanto, a mera aplicação de conhecimentos memorizados ou transmissão de saberes. Assim, para Perrenoud (1999), por meio da pedagogia das competências pretende-se que os estudantes se impliquem ativamente no confronto de "tarefas complexas" das quais possam resultar aprendizagens significativas e culturalmente pertinentes.

Os três domínios que compõem o conceito de competência, segundo Rabaglio (2004), são: conhecimento, habilidades e atitudes. Logo, a capacidade de combinar e mobilizar essas características qualifica-se como competência. O conhecimento é a compreensão teórica ou prática dos fatos e princípios sobre um assunto ou domínio de informação. As habilidades são desenvolvidas por meio de treinamento ou experiência que nos permite trabalhar com o conhecimento dado; e a atitude expressa valor e julga a pertinência da ação não só na qualidade da tarefa, mas também na ética do comportamento, na convivência participativa e em outros atributos humanos como iniciativa e criatividade. 
No âmbito do ensino brasileiro o desenvolvimento de competências foi incorporado à Lei de Diretrizes e Bases da Educação Nacional - LDBN no 9394/96, a partir da qual o Ministério da Educação (MEC) estabeleceu orientações para todos os níveis da educação nacional por meio de diretrizes, parâmetros e referenciais curriculares.

A Resolução CNE/CES n ${ }^{\circ}$ 5, de 8 de março de 2004 estabelece as Diretrizes Curriculares Nacionais do Curso de Graduação em Design que determinam as competências mínimas para os graduados em design. As diretrizes curriculares nacionais servem de referência para as faculdades na organização dos cursos superiores, permitindo flexibilidade na construção dos currículos. Esta resolução aborda por meio do seu projeto pedagógico os seguintes elementos estruturais:

A organização do curso de que trata esta Resolução se expressa através do seu projeto pedagógico, abrangendo o perfil do formando, as competências e habilidades, os componentes curriculares, o estágio curricular supervisionado, as atividades complementares, o sistema de avaliação, a monografia, o projeto de iniciação científica ou o projeto de atividade, como trabalho de conclusão de curso - TCC, componente opcional da Instituição, além do regime acadêmico de oferta e de outros aspectos que tornem consistente o referido projeto pedagógico (p. 01, Art. $2^{\circ}$ ).

O documento (quadro 1) orienta que o curso de graduação em design deve possibilitar a formação profissional que revele competências para:

I - Capacidade criativa para propor soluções inovadoras, utilizando domínio de técnicas e de processo de criação;

II - Capacidade para o domínio de linguagem própria expressando conceitos e soluções, em seus projetos, de acordo com as diversas técnicas de expressão e reprodução visual;

III - Capacidade de interagir com especialistas de outras áreas de modo a utilizar conhecimentos diversos e atuar em equipes interdisciplinares na elaboração e execução de pesquisas e projetos;

IV - Visão sistêmica de projeto, manifestando capacidade de conceituá-lo a partir da combinação adequada de diversos componentes materiais e imateriais, processos de fabricação, aspectos econômicos, psicológicos e sociológicos do produto;

V - Domínio das diferentes etapas do desenvolvimento de um projeto, a saber: definição de objetivos, técnicas de coleta e de tratamento de dados, geração e avaliação de alternativas, configuração de solução e comunicação de resultados;

VI - Conhecimento do setor produtivo de sua especialização, revelando sólida visão setorial, relacionado ao mercado, materiais, processos produtivos e tecnologias abrangendo mobiliário, confecção, calçados, joias, cerâmicas, embalagens, artefatos de qualquer natureza, traços culturais da sociedade, softwares e outras manifestações regionais;

VII - Domínio de gerência de produção, incluindo qualidade, produtividade, arranjo físico de fábrica, estoques, custos e investimentos, além da administração de recursos humanos para a produção;

VIII - Visão histórica e prospectiva, centrada nos aspectos socioeconômicos e culturais, revelando consciência das implicações econômicas, sociais, antropológicas, ambientais, estéticas e éticas de sua atividade.

\section{Quadro 1: Competências e habilidades}

Fonte: Portal.mec.gov.br

As diretrizes estabelecem que os cursos de graduação em design devem contemplar conteúdos e atividades que atendam alguns eixos interligados de formação (quadro 2). 
Conteúdos básicos: Estudo da história e das teorias do Design em seus contextos sociológicos, antropológicos, psicológicos e artísticos, abrangendo métodos e técnicas de projetos, meios de representação, comunicação e informação, estudos das relações usuário/objeto/meio ambiente, estudo de materiais, processos, gestão e outras relações com a produção e o mercado;

Conteúdos específicos:Estudos que envolvam produções artísticas, produção industrial, comunicação visual, interface, modas, vestuários, interiores, paisagismos, design e outras produções artísticas que revelem adequada utilização de espaços e correspondam a níveis de satisfação pessoal;

Conteúdos teórico-práticos: Domínios que integram a abordagem teórica e a prática profissional, além de peculiares desempenhos no estágio curricular supervisionado, inclusive com a execução de atividades complementares específicas, compatíveis com o perfil desejado do formando.

\author{
Quadro2: Conteúdos \\ Fonte: Portal.mec.gov.br
}

A falta de especificação para diferentes habilitações (design gráfico, produto, moda, entre outras) e a descontextualização do ambiente cultural onde os cursos se desenvolvem, oferecem uma maior liberdade para que as Universidades definam sua matriz curricular.

Entretanto, para Angélico e Oliveira (2017), esta liberdade e o viés tecnicista e linear das diretrizes possibilitam que os cursos de design não ofereçam uma abordagem crítica aos seus alunos. Não considerar as reflexões mais humanistas sobre as transformações de cunho comportamental, ético, social e sustentável voltados para o cenário atual, só reforça o interesse político em focar no crescimento industrial e econômico, reproduzindo desigualdades e desconsiderando o poder do design como agente transformador.

Estas visões voltadas ao mundo do trabalho, dissociadas de questões mais amplas, "têm como objetivo racionalizar, otimizar e adequar a força de trabalho face às demandas do sistema produtivo" (Deluiz, 2010). Nesta perspectiva as competências visam resultados para contribuição econômica e social de forma que as pessoas são avaliadas por aquilo que conseguem entregar como resultado.

.. a noção de competência é fortemente polissêmica, tanto no mundo do trabalho quanto na esfera da educação. Esta polissemia se origina das diferentes visões teóricas que estão ancoradas em matrizes epistemológicas diversas e que expressam interesses, expectativas e aspirações dos diferentes sujeitos coletivos, que possuem propostas e estratégias sociais diferenciadas e buscam a hegemonia de seus projetos políticos (DELUIZ, 2010).

Num mundo em constantes mudanças onde as tecnologias permitem outras formas de aprendizado, as instituições de ensino superior não são o único caminho para o desenvolvimento de competências. Em muitos casos, a necessidade por competências específicas para atuar em projetos que requerem conhecimentos específicos sobre tecnologias emergentes, exigem que estes profissionais busquem alternativas que não o ensino formal.

Nas organizações que trabalham com tecnologias emergentes, estas competências específicas estão sendo construídas concomitantemente com as atividades diárias dos designers, não sendo ainda uma prática recorrente, a formalização destas. Sendo assim, um caminho para a construção de um quadro de competências para o design do futuro, seria a identificação destas organizações, de profissionais, docentes e discentes que possam ser fonte de dados sobre novas áreas de atuação orientadas pelas tecnologias emergentes. 
Para Parry (1996 apud Cidral et al., 2001) o sucesso da abordagem de competências depende da forma com que os modelos são construídos, sendo que estes podem ser construídos a partir de um modelo validado ou do desenvolvimento de um modelo como mostra o quadro 3 .

\begin{tabular}{|c|c|}
\hline Começar com um modelo validado & Começar a partir do zero \\
\hline $\begin{array}{l}\text { 1. Identificar áreas de atuação profissionais } \\
\text { do egresso. } \\
\text { 2. Identificar organizações e profissionais } \\
\text { que possam ser fonte de dados sobre as } \\
\text { áreas de atuação, atividades e competências } \\
\text { profissionais. }\end{array}$ & $\begin{array}{l}\text { 1. Identificar áreas de atuação e atividades profissionais } \\
\text { do egresso. } \\
\text { 2. Identificar organizações e profissionais que possam } \\
\text { ser fonte de dados sobre as áreas de atuação, atividades } \\
\text { e competências profissionais. } \\
\text { 3. Entrevistar os profissionais sobre as áreas de atuação, } \\
\text { atividades e competênciais profissionais. }\end{array}$ \\
\hline $\begin{array}{l}\text { 3. Realizar uma pesquisa ou conduzir } \\
\text { um painel que inclua uma amostra } \\
\text { representativa da população profissional } \\
\text { para testar o grau de relevância e } \\
\text { importância das competências } \\
\text { identificadas. } \\
\text { 4. Analisar os dados e refinar o modelo. } \\
\text { 5. Finalizar o modelo. }\end{array}$ & $\begin{array}{l}\text { 4. Observar profissionais que atuam nas atividades } \\
\text { previstas (se houver). } \\
\text { 5. Desenvolver um modelo de competências preliminar. } \\
\text { 6. Realizar uma pesquisa ou conduzir um painél que } \\
\text { inclua uma amostra representativa da população } \\
\text { profissional para testar o grau de relevância e } \\
\text { importância das competências identificadas. } \\
\text { 7. Analisar os dados e refinar o modelo. } \\
\text { 8. Finalizar o modelo. }\end{array}$ \\
\hline
\end{tabular}

Quadro3: Modelo de competências (Cidral et al. 2001 adaptado de Parry, 1996)

Para construir um quadro de competências (conhecimentos, habilidades e atitudes) para o design considerando as novas práticas habilitadas por tecnologias emergentes, seria necessário a busca por um modelo validado para aplicá-lo nestas circunstâncias específicas.

Segundo Campion et al. (2011), para construir um quadro de competência, tarefas e habilidades precisam ser coletadas para cobrir o domínio selecionado. Logo, a consulta a especialistas e documentação existente deve ser identificada. No entanto as competências para o futuro precisam ser pensadas a partir de cenários ainda incipientes, onde empresas e indivíduos estão experimentando práticas criativas híbridas, novos modelos de organização e de trabalho, que transcendem as fronteiras conceituais e disciplinares tradicionais. Não há especialistas e sim pessoas que estão experimentando suas competências na prática e a documentação sobre tarefas também não foram encontradas.

Na revisão de literatura não foram encontrados modelos que orientem a construção de competências para o futuro, apontando a necessidade de se criar técnicas específicas a respeito de atividades profissionais que existirão no futuro e que não podem estar pautadas em modelos de competências existentes na atualidade.

Wickramasinghe \& De Zoyza (2009) alertam para importância de estabelecer competências para o futuro e não apenas as competências do passado, assim o quadro de competências deve refletir as necessidades atuais e futuras. Campion et al. (2011) sugerem que a construção de um modelo de competências para o futuro seja realizada a partir de cenários de futuro com grupos focais. 
Os modelos encontrados e as orientações metodológicas indicadas não contemplam de maneira integral as necessidades encontradas nesta pesquisa, sendo necessário a construção de um modelo de competências a "partir do zero" como indica Perry (1996).

\section{Método}

O método Design Science Research (DSR) fundamenta e operacionaliza esta pesquisa, buscando entender o problema, construir e avaliar o artefato a ser desenvolvido. Este método (DSR) "tem como objetivo conceber e validar sistemas que ainda não existem, seja criando, recombinando, alterando produtos, processos, e métodos para melhorar as situações existentes" Dresch (2015).

A classificação dos artefatos da DSR, segundo Dresch (2015), são: constructos, modelos, métodos, instanciações e design propositions. O modelo foi escolhido, como artefato desta pesquisa, por corresponder a um conjunto de proposições ou declarações que expressam as relações entre os constructos (March e Smith, 1995 apud. Dresch, 2015). Um modelo que representa uma proposta de solução para busca das competências do design orientada para o futuro, que capture a estrutura da realidade para ser uma representação útil.

A figura 1 mostra as estratégias metodológicas que orientam esta pesquisa.

\section{DESIGN SCIENCE RESEARCH}

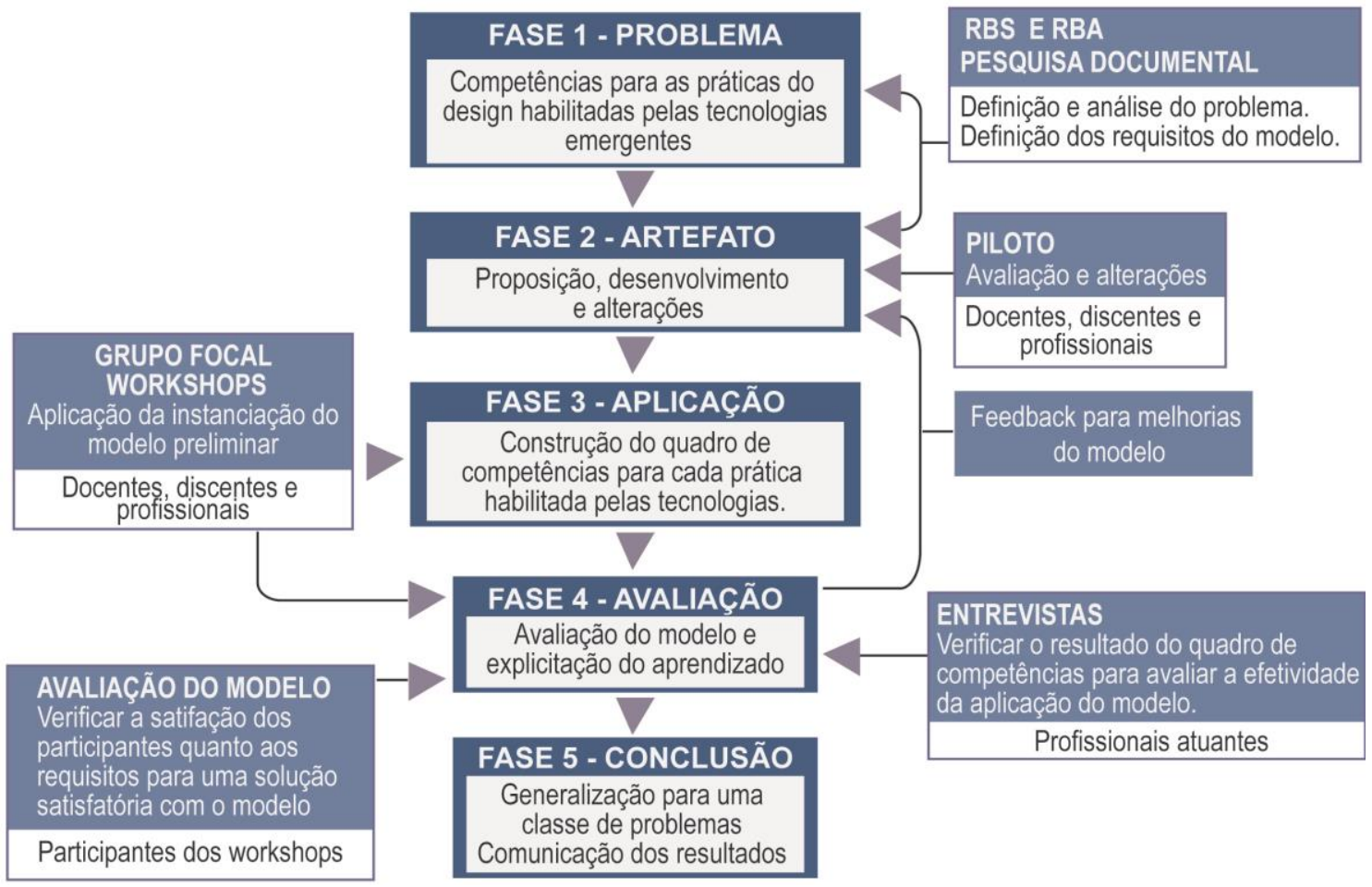

Figura 1: Estratégias metodológicas Fonte: Os autores baseados em Dresch (2015)

A pesquisa documental sobre as atuais competências do design e os dados bibliográficos orientaram a compreensão do problema para definição dos constructos, identificação do artefato e determinação dos requisitos do modelo. 
Os requisitos definidos para o modelo são (quadro 4):

1. Identificar e descrever as tecnologias emergentes com potencial para impactar a profissão de design.

2. Identificar e contrastar obstáculos e oportunidades destas tecnologias.

3. Estimular e estruturar a reflexão sobre as potenciais mudanças advindas da adoção das tecnologias incentivando os participantes a imaginar cenários onde o design pode ser impactado por elas.

4. Proporcionar o compartilhamento de diferentes visões sobre o problema.

5. Analisar como a convergência e integração entre tecnologias impactam as práticas do design.

6. Identificar as competências a partir das práticas potenciais para o processo de design relacionadas as tecnologias emergentes.

7. Incentivar a construção colaborativa das competências com múltiplos atores.

8. Analisar os resultados com os participantes e profissionais atuantes.

Quadro 4: Requisitos para o modelo

Fonte: Elaborado pelos autores

O desenvolvimento do artefato foi realizado na segunda etapa seguindo os requisitos estabelecidos e considerando os resultados do workshop piloto.

Para verificar a efetividade e fornecer feedback para melhorias e correções foi realizada a aplicação do modelo preliminar em seis workshops para a construção participativa do quadro de competências para cada tecnologia.

$\mathrm{Na}$ fase de avaliação, o resultado obtido com o modelo (quadro de competências), foi apresentado a todos os participantes para validação e correção dos resultados. Para complementar a avaliação foram realizadas entrevistas semiestruturadas, com designers atuantes em tecnologias emergentes. Para avaliar o modelo foram enviados formulários a todos os participantes com os critérios para uma solução satisfatória (fig.2).

ESTRATÉGIA DE VALIDAÇÃO

\begin{tabular}{l}
\hline Grupo focal confirmatório \\
$\begin{array}{l}\text { Formulário para avaliação do } \\
\text { quadro de competências }\end{array}$ \\
\hline
\end{tabular}

Entrevistas com profissionais atuantes no mercado

Formulário com os requisitos da solução satisfatória do modelo

\section{OBJETIVO}

Demonstrar a utilidade dos artefatos desenvolvidos no campo de aplicação

Avaliar a credibilidade dos achados,

a interpretação da pesquisadora, os resultados obtidos e sugerir alterações.

Avaliar o resultado das competências construídas nos workshops.

Avaliar a satisfação dos envolvidos em relação ao modelo e resultados das competências.

\section{PARTICIPANTES}

01 workshop em Joinville - P\&D 2018

06 workshops em Curitiba - UTFPR

Professores, estudantes e profissionais que participaram dos workshops

Designers atuantes no mercado

Todos os participantes dos workshops

Figura 2: Estratégias de validação Fonte: Elaborado pelos autores

Os diversos constructos que foram levantados na revisão bibliográfica tiveram como objetivo organizar uma estrutura conceitual na busca de um modelo funcional para estabelecer as competências do design. $\mathrm{O}$ modelo pretende instigar a reflexão acadêmica sobre as potenciais mudanças na prática profissional proporcionadas pelas tecnologias emergentes e suas consequências para o ensino. 
A figura 03 ilustra o modelo preliminar, construído a partir da lista de requisitos.

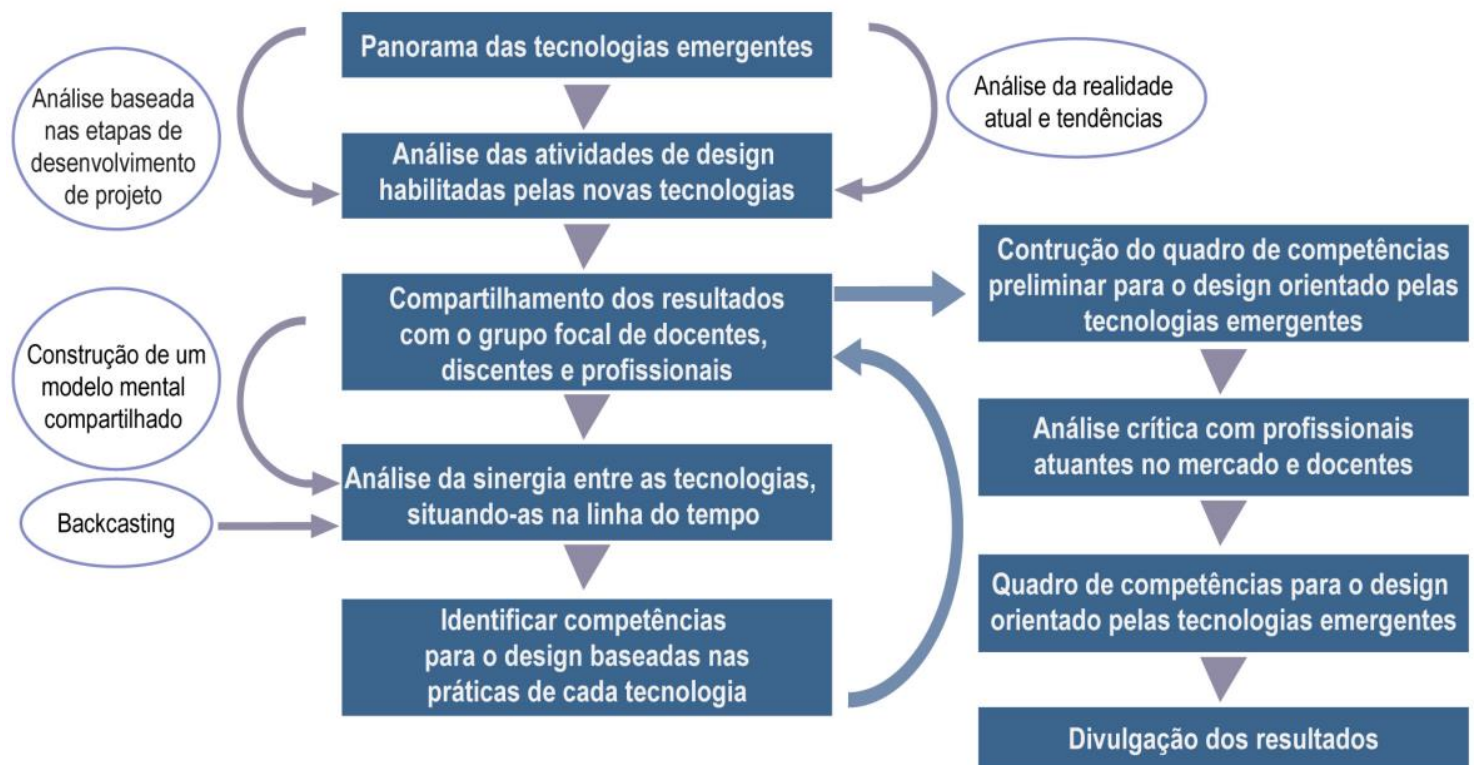

Figura 3: Modelo preliminar

Fonte: Elaborado pelos autores

O modelo apresentado (fig.3) inicia com a identificação e descrição das tecnologias emergentes (ex: Internet das coisas, Inteligência artificial, Realidade digital ${ }^{1}$, entre outras) que tem o potencial para afetar as práticas do design, baseado na análise da realidade atual e tendências para o futuro. Posteriormente devem ser identificados e contrastados obstáculos, oportunidades e a possível sinergia entre estas tecnologias.

A análise baseada nas etapas de desenvolvimento de projeto (identificação do problema, fases do projeto, pessoas envolvidas e saída/resultado) para a prática do design relacionada a cada tecnologia são desenhadas a partir das informações obtidas sobre as tecnologias.

São então compartilhados os resultados da pesquisa sobre tecnologias emergentes e seu impacto na profissão com grupo focal (workshop) de docentes, discentes e profissionais com o objetivo de construir um modelo mental compartilhado. Nesta fase o objetivo é provocar a curiosidade dos participantes em relação ao futuro do design.

As práticas para o processo de design a partir das tecnologias emergentes são apresentadas para que o grupo possa discutir como a sinergia entre estas tecnologias afetam o design considerando um espaço de tempo determinado (Ex: 2019 a 2030).

Utilizando a ferramenta backcasting para construir pontes a partir do presente para um futuro desejável, de forma retrospectiva, identificam-se os passos intermediários que levam a esse futuro e as principais escolhas que devem ser feitas agora e num futuro próximo. Esta abordagem permite desenhar imagens plausíveis do futuro para o design definindo as mudanças necessárias que devem ser feitas a partir do presente para alcançar futuros preferíveis.

\footnotetext{
${ }^{1}$ A realidade aumentada / virtual / mista, são componentes da chamada Realidade Digital ou "XR".
} 
Nesta fase são apresentados aos participantes o quadro de backcasting (fig. 4) e os cartões que descrevem as tecnologias e as práticas baseadas no processo de design (fig.5), provocando discussões sobre este contexto. Os participantes estabelecem as conexões entre as tecnologias elencadas e a data aproximada do impacto de cada tecnologia na profissão do designer preenchendo o quadro de backcasting em ordem cronológica com os cartões de cada tecnologia.

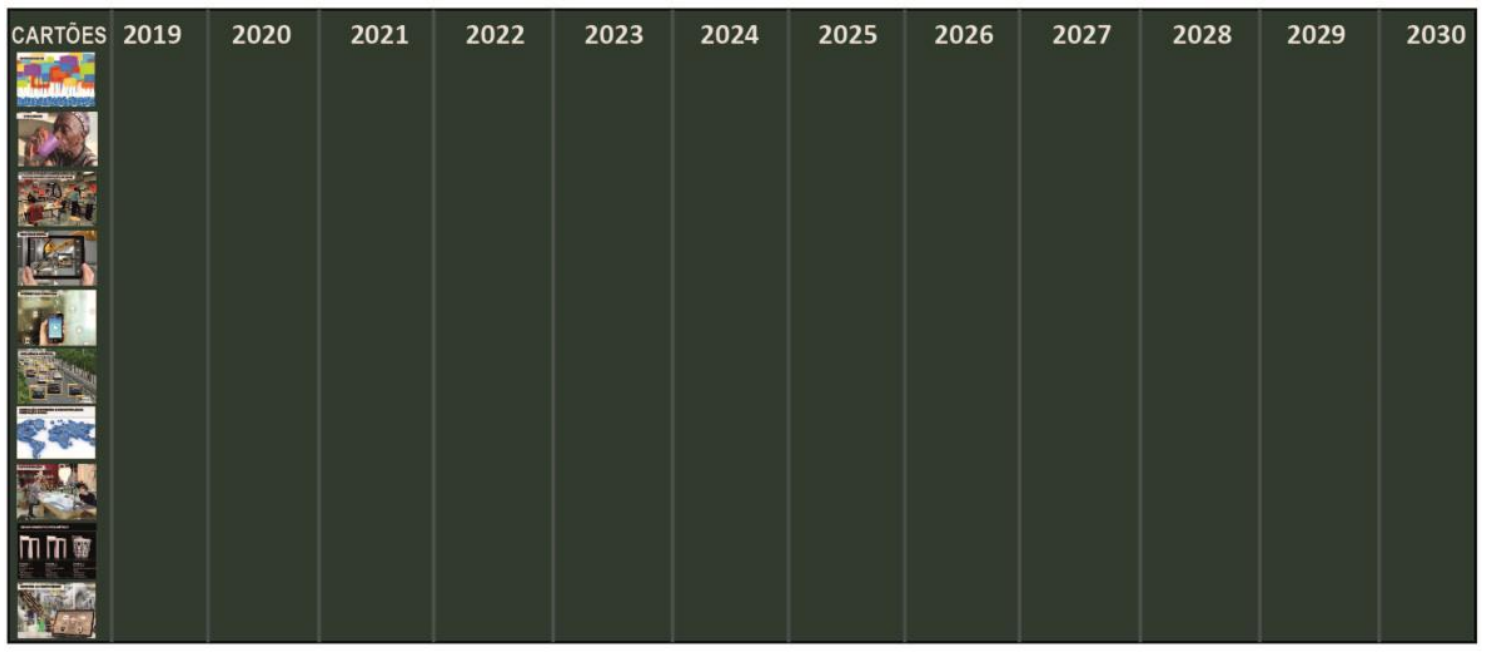

Figura 4: Quadro de backcasting (dimensões: 1000x500mm) Fonte: Elaborado pelos autores

\begin{tabular}{|l|l|}
\hline INTERNET DAS COISAS (lot) & $\begin{array}{l}\text { Identificação da necessidade: Uso de produtos inteligentes como } \\
\text { suporte de informação para entrada de dados para iniciar o projeto } \\
\text { ou modificar o produto em uso. } \\
\text { A experiência do usuário pode ser obtida/analisada em tempo real } \\
\text { oportunizando a identificação de necessidades em tempo real. }\end{array}$ \\
$\begin{array}{l}\text { Fases: Traballho de forma cruzada com equipes de análise de dados } \\
\text { etodos os participantes do sistema. } \\
\text { Gerenciamento de ciclo de vida de produtos desde a criação até o descarte. } \\
\text { Design da interação entre ambiente, produtos, humanos e não humanos. } \\
\text { Mudanças nos produtos podem ser prototipadas de forma cyber-física. }\end{array}$ \\
$\begin{array}{l}\text { Stakeholders: o produto pode ser considerado um participante ativo no } \\
\text { processo de design. } \\
\text { Envolvimento de múltiplos stakholders e empresas. } \\
\text { Saída: Maior personalização de produtos e serviços. A grande quantidade } \\
\text { de dados gerados podera se tornar um produto de direito próprio e } \\
\text { proporcionar novas formas de monetização. }\end{array}$
\end{tabular}

Figura 5: Frente e verso do cartão da tecnologia IoT Fonte: Elaborado pelos autores

A construção colaborativa e dialogada de competências para o design considerando cada tecnologia e suas convergências é realizada por meio de formulário (quadro 5). Neste os participantes apontam os obstáculos e oportunidades que cada tecnologia oferece e quais as competências (conhecimentos, habilidades e atitudes) esperadas para a prática do design. 


\begin{tabular}{|l|l|}
\hline \multicolumn{2}{|c|}{ INTERNET DAS COISAS } \\
\hline Obstáculos \\
\hline \multicolumn{2}{|l|}{ Oportunidades } \\
\hline \multirow{2}{*}{$\begin{array}{l}\text { Competências } \\
\text { (reforçar as já } \\
\text { existentes ou } \\
\text { elencar novas) }\end{array}$} & Conhecimentos \\
\cline { 2 - 2 } & Habilidades \\
\cline { 2 - 3 } & Atitudes \\
\hline
\end{tabular}

Quadro 5: Formulário de competências

Fonte: Elaborado pelos autores

Finalizadas as tarefas do quadro de backcasting e o preenchimento dos formulários de competências para cada tecnologia, o mediador compila todos os resultados e elabora uma documentação descritiva da solução, para cada tecnologia, compartilhando com todos os participantes para que estes possam avaliar os resultados sugerindo melhorias. Na figura 6 estão representados os seis passos dos workshops para a construção das competências.

WORKSHOP: Tecnologias digitais emergentes e as potenciais mudanças para as práticas e competências do design

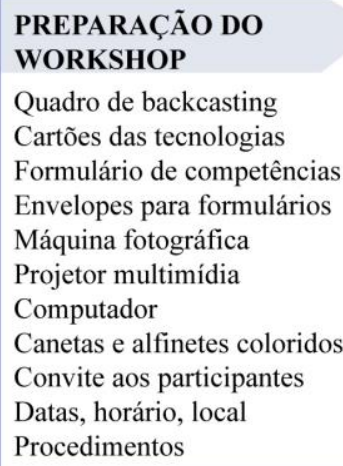

1. IMERSÃO
Mídia digital para
exposição dialogada.
Exploração das tecnologias
emergentes e sensibilização
quanto as possíveis
mudanças para o design.
CARTÕES
Práticas de design
habilitadas pelas
tecnologias emergentes.

2. DISCUSSÃO
BACKCASTING
Conexões e cronologia
das tecnologias
emergentes
FORMULÁRIO
Desafios e Oportunidades
Competências:
conhecimentos
habilidades e atitudes.

\section{DECISÃO}

Situar no tempo quando a prática dos designers será impactada pelo uso destas tecnologias. Definir conhecimentos, habilidades e atitudes para novas práticas habilitadas pelas tecnologias.

\begin{tabular}{|l||l|l|}
\hline \multicolumn{1}{|l|}{ 4. DOCUMENTAÇÃO } & 5. AVALIAÇÃO & $\begin{array}{l}\text { 6. CORREÇÕES E } \\
\text { DIVULGAÇÃO }\end{array}$ \\
$\begin{array}{l}\text { Compilar os dados obtidos } \\
\text { em todos os workshops } \\
\text { referentes a cada tecnologia. }\end{array}$ & $\begin{array}{l}\text { Formulário eletrônico } \\
\text { com os resultados dos } \\
\text { workshops para análise } \\
\text { crítica dos participantes. }\end{array}$ & $\begin{array}{l}\text { Correções baseadas } \\
\text { nas análises e } \\
\text { entrevistas. }\end{array}$ \\
$\begin{array}{l}\text { Quadro de backcasting } \\
\text { Quadro de competências }\end{array}$ & $\begin{array}{l}\text { Entrevistas com designers } \\
\text { atuantes nas tecnologias } \\
\text { elencadas para avaliação } \\
\text { dos resultados (caso não } \\
\text { tenha havido avaliação } \\
\text { de todas as tecnologias. }\end{array}$ & $\begin{array}{l}\text { Elaboração descritiva } \\
\text { da solução modelada } \\
\text { para cada tecnologia. }\end{array}$ \\
Divulgação dos resultados \\
para todos os interessados.
\end{tabular}

Figura 6: Sequência de ações para os workshops Fonte: Elaborado pelos autores

Contando com a impossibilidade de reunir pessoas experientes em cada tecnologia analisada, após a avaliação feita pelos participantes são realizadas entrevistas com designers atuantes para avaliação dos resultados. A partir da narrativa dos profissionais entrevistados sobre as práticas, o quadro de backcasting e de competências são revisados, para construção final e divulgação dos resultados. 


\section{Resultados}

Para aplicação das instanciações do modelo foram realizados sete workshops com 38 participantes. Os seis primeiros workshops foram realizados nas dependências da UTFPR e contaram com 23 participantes, o sexto workshop foi realizado no Congresso P\&D Design 2018 com a participação 15 pessoas que foram divididas em cinco equipes (quadro 6).

\begin{tabular}{|c|c|c|c|c|}
\hline Data & Local & Professores & Alunos & Profissionais \\
\hline set 2018 (piloto) & UTFPR & 01 & 03 & 01 \\
\hline out 2018 & UTFPR & 05 & - & 01 \\
\hline out 2018 & UTFPR & 02 & 01 & 01 \\
\hline out 2018 & UTFPR & 03 & - & - \\
\hline out 2018 & UTFPR & 02 & - & - \\
\hline out 2018 & UTFPR & 01 & 01 & 01 \\
\hline nov 2018 & $\mathrm{P} \& \mathrm{D}$ & - & 03 & - \\
\hline nov 2018 & $P \& D$ & 01 & 01 & 01 \\
\hline nov 2018 & $P \& D$ & 01 & 01 & 01 \\
\hline nov 2018 & $P \& D$ & 01 & 01 & 01 \\
\hline nov 2018 & $P \& D$ & - & 02 & 01 \\
\hline
\end{tabular}

As tecnologias emergentes elencadas para estes workshops foram: crowdsourcing, movimento maker, autoprodução, open design, fabricação distribuída e descentralizada, internet das coisas, indústria 4.0, realidade digital, inteligência artificial, design generativo, considerando neste trabalho, que tecnologias são a construção e o uso social de ferramentas (ex: artefatos físicos, métodos, modelos, heurísticas, entre outros).

Este exercício prospectivo participativo, de imaginar cenários para o design vinculados as tecnologias emergentes, proporcionou a oportunidade de troca de informações e conhecimento entre professores, alunos e profissionais com experiências diversas. A discussão sobre a confluência e integração entre as tecnologias foi determinante para a escolha do posicionamento das tecnologias na linha do tempo.

Ao final da realização de todos os workshops foram compilados os dados referentes a cada tecnologia. A figura 7 mostra o exemplo do quadro para IoT onde a maioria dos participantes considera que esta tecnologia já afeta as práticas do design.

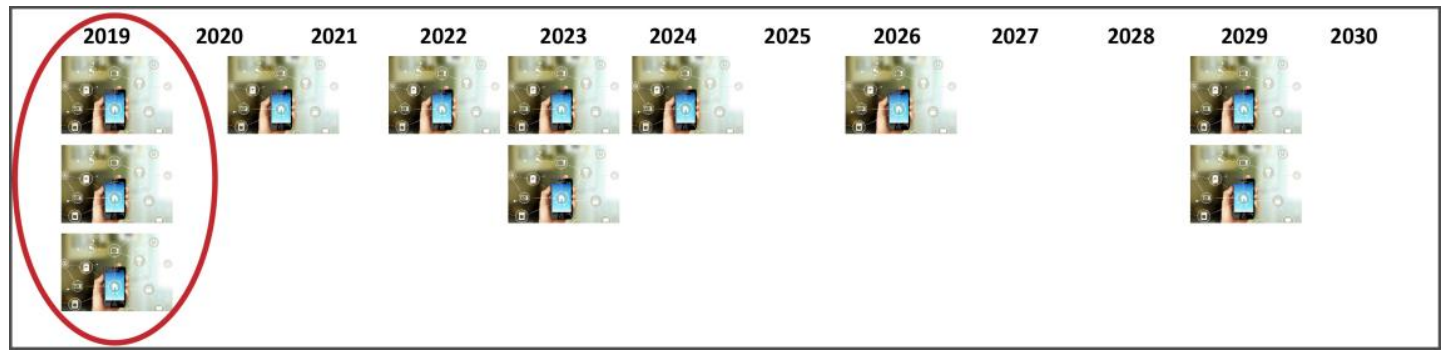

Figura 7: Exemplo do resultado do quadro de backcasting para IoT Fonte: Elaborado pelos autores

O resultado dos formulários sobre competências gerou uma tabela (quadro 7), onde as competências elencadas estão divididas em conhecimentos, habilidades e atitudes que os designers precisam desenvolver para as novas práticas habilitadas pelas tecnologias emergentes. 


\begin{tabular}{|l|l|l|}
\hline & \multicolumn{1}{|c|}{ INTERNET DAS COISAS } & \\
Conhecimentos & Habilidades & Atitudes \\
Tipologia de conexões & Programação & Visão sistêmica \\
Comportamento humano & Personalização, prototipação de hardware & Considerar diversidade de atores \\
Design de serviço & Trabalho equipe, relacional, & Ética, juízo e empatia \\
Ergonomia, ciência e design de informação & Gerência de dados, inovação & Trabalho multidisciplinar \\
Linguagem, comunicação e interface & Visão sistêmica, domínio de linguagem & Abertura cultural \\
Entendimento técnico das tecnologias & Co-criação & Pensamento aberto para mudanças \\
Relações sistêmicas das tecnologias & Pensamento sistêmico & Disposição, gestão de projetos \\
Programação, Big Data & Resolução de problemas complexos & Agilidade \\
UX design, ecologia & Capacidade de materialização & Flexibilidade, colaboração \\
Multidisciplinares & Habilidade de negociação & \\
\hline
\end{tabular}

Quadro 2: Exemplo do resultado de competências para IoT Fonte: Elaborado pelos autores

Os resultados dos quadros de backcasting e competências foram compartilhados com todos os participantes para que estes pudessem rever, comparar os resultados e sugerir mudanças.

Após a análise de todas as respostas (complementadas pela escuta do áudio dos workshops), buscou-se transformar os dados obtidos em documentação totalmente descritiva da solução modelada por meio de um quadro de competências para cada tecnologia.

Como competência comum para a prática do design relacionada com todas as tecnologias estabeleceu-se dois itens principais:

1. Capacidade de decidir sobre os limites legais, éticos e culturais do uso pessoal e socialmente responsável das tecnologias, compreendendo os riscos potenciais.

2. Compreender, analisar e avaliar o impacto das tecnologias nos contextos social, econômico e cultural.

O quadro descritivo final de competências para o design foi elaborado para cada uma das tecnologias estudadas. $\mathrm{O}$ quadro 8 mostra o exemplo das competências elaboradas para prática do design habilitada pela internet das coisas.

\begin{tabular}{|l|}
\hline \multicolumn{1}{|c|}{ Internet das Coisas } \\
\hline Conhecimentos sobre fundamentos, aplicações e tipologia de conexões. \\
\hline $\begin{array}{l}\text { Conhecimentos em Design de serviço, Design de experiência do usuário (UX) e Design de interação } \\
\text { (UI). }\end{array}$ \\
\hline Conhecimentos em Ciência da informação e design de informação. \\
\hline Conhecimentos sobre comportamento, ergonomia cognitiva e neurociência. \\
\hline $\begin{array}{l}\text { Conhecimento básico em programação, big data, sistemas de segurança, criptografia, Inteligência } \\
\text { artificial (ênfase em NLP - natural language processing) e eletrônica. }\end{array}$ \\
\hline Conhecimentos em prototipagem de hardware e de produto (materialização). \\
\hline Habilidade em pensamento sistêmico e resolução de problemas complexos. \\
\hline Habilidade em trabalhar em equipe multidisciplinar, cocriação, negociação e gestão de projetos. \\
\hline Habilidade em personalização de produtos. \\
\hline Atitude colaborativa, alteridade, empatia e ética. \\
\hline Agilidade, flexibilidade e abertura para o novo. \\
\hline
\end{tabular}

Quadro 8: Quadro de competências final para IoT Fonte: Elaborado pelos autores

Considerando que participaram dos workshops pessoas envolvidas com: opendesign, realidade digital, movimento maker, produção distribuída e descentralizada, e que estes validaram as 
competências elencadas nos workshops por meio dos formulários eletrônicos, mostrou-se necessária a validação das competências para a prática do design habilitadas pelas tecnologias restantes. Buscou-se então, a validação com designers que trabalham com crowdsourcing, inteligência artificial, autoprodução, internet das coisas, design generativo e indústria 4.0.

\section{Discussão}

A maioria dos modelos orientados para estabelecer competências iniciam o processo reunindo especialistas (profissionais ou egressos) para descrever as tarefas que serão analisadas, para posteriormente determinar as competências necessárias. Listas e descrições de tarefas, especialistas, documentos com foco no desempenho e aprendizado e catálogos de tarefas, que orientam a maioria dos modelos para competências, são inexistentes para orientar um modelo que possa eleger competências para o design do futuro.

No modelo proposto nesta pesquisa não são descritas tarefas e não foram consultados especialistas no início do processo. Esta decisão foi tomada para que os participantes pudessem ter uma visão ampla das possibilidades oferecidas pelas tecnologias descartando uma análise operacional por tarefas. Outro motivo para não descrever tarefas está no fato de que explorar competências para um futuro próximo requer imaginar cenários nos quais o design pode transitar com os conhecimentos atuais e com competências que deverão ser elaboradas para práticas futuras.

Para partilhar e contrastar experiências, construindo um quadro de interesses e preocupações comuns, optou-se pela realização de workshops com grupos de indivíduos com maior diversidade. Apesar de exaustiva, a dinâmica em todos os workshops foi produtiva, pois os participantes se mostraram curiosos e participativos com o possível aprendizado gerado com a explanação sobre as tecnologias e o conhecimento compartilhado sobre experiências de mercado, ensino e aprendizado. Porém, recomenda-se a aplicação deste modelo considerando dividir as atividades por blocos, para não sobrecarregar os participantes e nem afetar os resultados por falta de tempo para conclusão das ideias.

Conclui-se que, após a aplicação e avaliação do modelo, a estrutura proposta para o modelo elaborado não requer modificações, porém para novas instanciações seguem algumas orientações:

1. Garantir a participação de pessoas atuantes no ensino, no mercado de trabalho, em instituições de fomento ao design, com experiências diversificadas.

2. A tarefa de elencar tecnologias norteadoras (consideradas relevantes para a área) deve ser realizada pelas pessoas envolvidas em conduzir o processo.

3. Os workshops devem ser realizados em três momentos e tempos distintos: primeiro o backcasting com feedbacks ao final da sessão, após uma pausa a realização do quadro de competências com novo feedback e uma última sessão para construção colaborativa do quadro de competências.

4. A condução da atividade deve ser realizada durante todo processo para que haja o entendimento dos conceitos abordados, para garantir que todos os participantes relatem suas experiências e participem da tomada de decisões. 
5. O trabalho deve ser conduzido por um mediador por equipe, com o máximo de 6 participantes para que a discussão entre estes seja profícua e possa resultar em consenso.

6. A construção final do quadro de competências deve ser realizada com a colaboração de todos os participantes, transformando as palavras e ideias em narrativas elaboradas e coerentes.

O modelo final com as sugestões de modificação para as instanciações futuras pode ser visualizado na figura 8 .

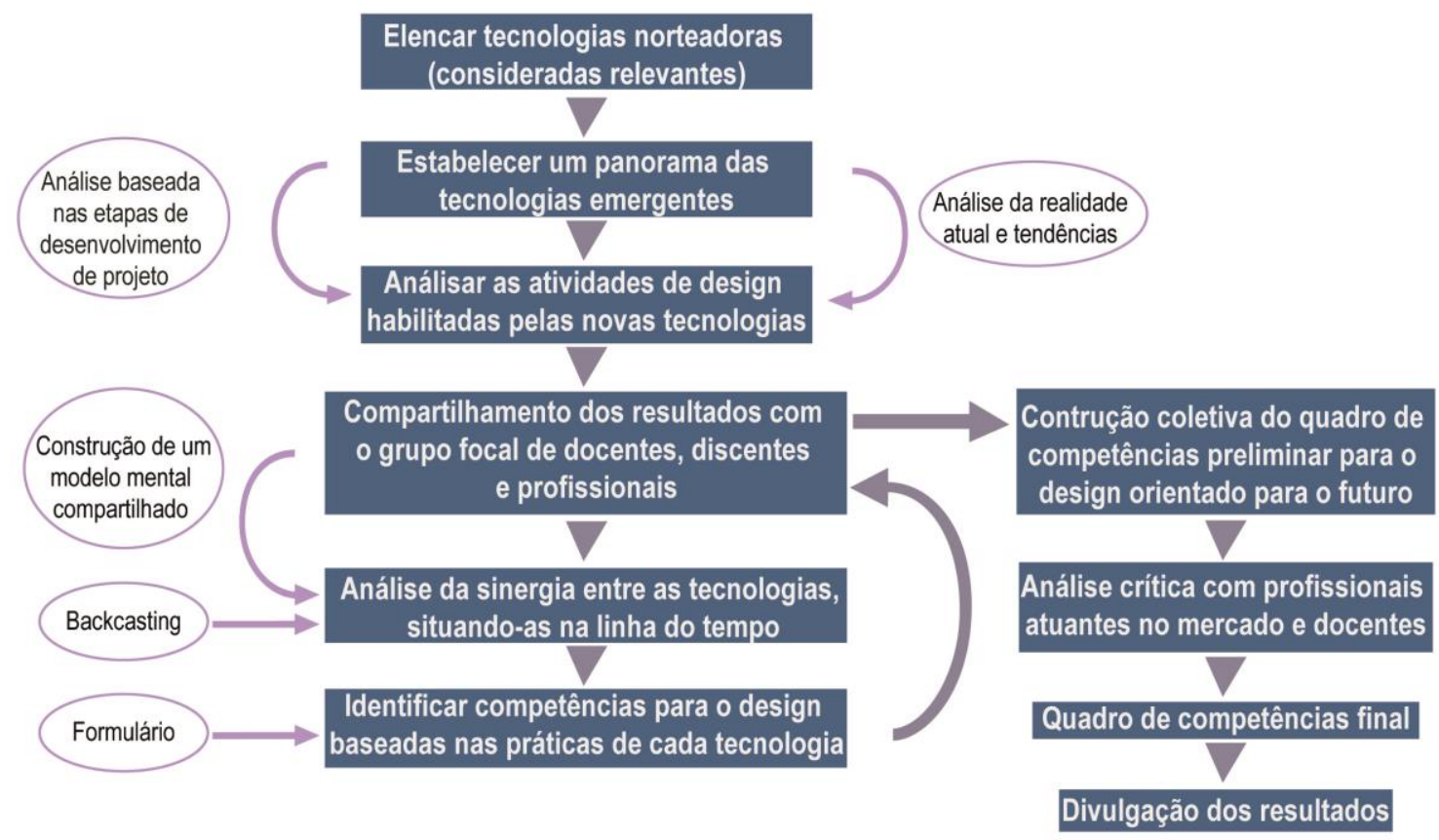

Figura 8: Modelo final

Fonte: Elaborado pelos autores

Quanto a utilidade do modelo proposto neste trabalho considera-se que este poderá ser utilizado por outros pesquisadores, de áreas diversas, para construir um quadro de competências para qualquer atividade que esteja habilitada por tecnologias emergentes com objetivos educacionais e profissionais.

Quanto ao resultado da aplicação do modelo neste trabalho, considera-se que o quadro de competências estabelecidas poderá ser utilizado para reelaboração da matriz dos cursos de design inserindo novas práticas para acompanhar as mudanças globais emergentes. Designers interessados em uma especialização nestas áreas poderão a partir destas competências buscar uma formação dentro ou fora do ensino regular.

Outra aplicação do resultado será a possibilidade de empresas que trabalham com estas tecnologias utilizarem este quadro de competências como referência para contratação de designers. 


\section{Considerações finais}

As tecnologias emergentes amplificam as possibilidades de atuação professional do design, tornam difusos os papéis até então estabelecidos, desvinculam o design da organização industrial, hibridizam e modificam práticas convencionais. Estas mudanças nas práticas do design não devem ser apenas acompanhadas pelo ensino, pois é necessário prever, antecipar, preparar-se para as mudanças previsíveis pela pró-atividade e agir para provocar mudanças desejadas.

Imaginar o futuro da profissão de designer para daqui a dez anos, baseado na situação atual e nas tendências para o futuro do mundo, possibilita traçar ações para um ensino de design preferível, onde o futuro próximo pode parecer menos incerto e mais provável.

As possibilidades de trabalho para o design do futuro, baseado nas tecnologias emergentes, orienta-se por novas práticas para as quais os designers devem estar habilitados. Portanto, verificou-se a necessidade do desenvolvimento de um modelo para construção participativa destas competências.

O modelo resultante desta pesquisa se aprofunda nas características e especificidades das tecnologias emergentes e analisa o impacto destas, na prática do design. O processo de backcasting e a construção dialogada das competências, objetivaram a construção de um modelo mental compartilhado provocando a interação social entre os atores, estimulando a imaginação, criando uma linguagem comum, reduzindo incoerências e estruturando a reflexão coletiva.

Os quadros de competências para o design habilitadas pelas dez tecnologias emergentes, construídos neste trabalho, oferecem um panorama preliminar e não se exaurem nesta pesquisa. Portanto, recomenda-se a aplicação do modelo para auxiliar a construção de competências em cursos de design para que os atores envolvidos possam discutir estas novas práticas, validar e complementar deste quadro.

Espera-se que ao construir um modelo para prever, antecipar e desenvolver competências para uma atuação consciente e crítica, os designers possam cumprir seus desígnios como transformadores sociais, incorporando novos valores às tecnologias, para que estas possam afetar de maneira positiva a vida das pessoas.

\section{Referências}

ANGÉLICO, A. M. D.; OLIVEIRA, M. C. M. O ensino do design no Brasil: currículos, ideologias e contemporaneidade. Educação, Cultura e Sociedade, v. 7, p. 604-615, 2017.

CAMPION, M.; FINK, A.; RUGGEBERG, A.; CARR, L.; PHILLIPS, G.; ODMAN, R. Doing competencies well: best practices in competency modeling. Personnel psychology, 64, 225262. Wiley Periodicals, 2011.

DELUIZ, N. O modelo das competências profissionais no mundo do trabalho e da educação: Implicações para o currículo. Boletim Técnico do Senac, Rio de Janeiro, v. 27, n. 3, p. 13-25, set. /dez. 2001.

DE VERE, I. Industrial Design 2.0: A Renaissance. International conference on engineering and product design education 5 \& 6 september, 2013. 
DRESCH, A.; LACERDA, D.P.; ANTUNES, JR, J.A.V. Design Science Research: método de pesquisa para avanço da ciência e tecnologia. Porto Alegre: Bookman, 2015.

CIDRAL, A.; KEMEZINSKI, A.; ABREU, A. A abordagem por competências na definição do perfil do egresso de cursos de graduação. Cobenge, p. 145-151, 2001.

EINSIEDEL, E. F. Emerging technologies: from hindsight to foresight. UBC Press, 2009

IMBESI, L. Design for post-industrial societies: re-thinking research and education for contemporary innovation, Ottawa, Carleton University, SID - School of Industrial Design, 2011.

LOY, J. The future for design education: preparing the design workforce for additive manufacturing. International Rapid Manufacturing, v.5, n. 2, 2015.

MANZINI, E. Design Schools as Agents of (Sustainable) Change: A Design Labs Network for an Open Design Program. In: International Symposium for Design Education Researchers, 1, 2011, Paris, França. Researching Design Education: Symposium Proceedings. Aalto, Finland: Cumulus Association/Design Research Society - DRS. p. 9-16, 2011.

PERRENOUD, Philippe. MAGNE, B. C (org.). Construir as competências desde a escola. Porto Alegre: Artmed, 1999.

RABAGLIO, M. O. Ferramentas de avaliação de performance com foco em competências. Rio de Janeiro: Qualitymark, 2004.

SMITH, Adrian; HIELSCHER, Sabine; DICKEL, Sascha; SODERBERG, Johan; van OOST, Ellen. Grassroots digital fabrication and makerspaces: reconfiguring, relocating and recalibrating innovation? Science and Technology Policy Research. University of Sussex, 2013.

WICKRAMASINGHE, V., \& De Zoyza, N. A comparative analysis of managerial competency needs across areas of functional specialization. Journal of Management Development, 28(4), 344-360, 2009.

WINNER, L. Do Artifacts Have Politics? In The Whale and the Reactor: A Search for Limits in an Age of High Technology, edited by Langdon Winner, 19-39. Chicago: University of Chicago Press, 1986.

\section{Sobre os autores}

\section{Christiane Maria Ogg Nascimento Gonçalves Costa}

Doutora em Design de Sistemas de Produção e Utilização pela UFPR, Mestre em inovação pela UTFPR, Bacharel em Desenho Industrial pela PUC Curitiba.

Professora adjunta na UTFPR, Departamento Acadêmico de Desenho Industrial.

christiane.ogg@gmail.com

\section{Alexandre Vieira Pelegrini}


$\mathrm{PhD}$ (doutor) em Design Research pela Brunel University, Mestre em Engenharia Mecânica pela UFPR, Bacharel em Desenho Industrial pela UDESC.

Professor adjunto na UTFPR, Departamento Acadêmico de Desenho Industrial.

avpelegrini@gmail.com 